\title{
Influence of Travel Behavior, Personal Preferences, and Lifestyle on Perceived Convenience to Amenities among Calgary Residents
}

Transportation Research Record 2019, Vol. 2673(8) 508-522

(C) National Academy of Sciences: Transportation Research Board 2019 Article reuse guidelines: sagepub.com/journals-permissions DOI: $10.1177 / 0361198119844967$ journals.sagepub.com/home/trr (SSAGE

\author{
Mark Onderwater', Geneviève Boisjoly ${ }^{2}$, and Ahmed El-Geneidy ${ }^{3}$
}

\begin{abstract}
The presence of essential amenities, such as grocery stores, parks, and employment, within convenient distances impacts individuals' travel behavior and quality of life. Whereas what is perceived as a convenient distance varies among individuals, the goal of this research is to better understand perceived convenience in the context of differing lifestyles, sociodemographic characteristics, and personal preferences. Using an online travel behavior survey with a sample of 7II residents from Calgary, Canada, we segmented individuals into eight distinct groups based on travel behavior and personal characteristics. We then examined their perceived convenience to reach various amenities among each group, and the actual distances to these amenities. Our results reveal eight distinct typologies that differ according to mode choice, lifestyle, neighborhood characteristics, and trip satisfaction. We observe that distance negatively affects reported convenience to work, grocery stores, and parks, but reported convenience is also closely related to modes available as well as to transport and home location options that meet individuals' preferences. Typologies in which individuals are able to select their preferred transport options or home location typically report a higher convenience of access to various destinations, and this is especially true for typologies with high cycling, walking, and public transport mode shares. This study demonstrates the importance of providing individuals with a variety of affordable options in relation to transport mode and home locations, which can be of interest to researchers and planners concerned with improving convenience of access to local amenities by sustainable modes.
\end{abstract}

Designing mixed and dense cities is increasingly used as a strategy to increase local accessibility, and thereby support sustainable transport modes (walking, cycling, and public transport), in an effort to reduce car dependency. Such strategies aim to bring destinations closer to origins, which improves the convenience of, and participation in, sustainable modes $(1,2)$. What is perceived as convenient, however, differs from one individual to another, and is influenced by personal preferences, available and habitual mode choices, types of destinations, socioeconomic characteristics, and lifestyles $(3,4)$. To better understand differing perceptions in relation to transport, segmentation analyses have been used to identify different groupings of similar travel habits/attitudes within the population, but typically focus on a specific mode. This approach is valuable in developing targeted strategies to achieve a variety of objectives. Yet to our knowledge, no studies have used a similar approach to understand the relationship between travel behavior across a variety of mode users, differing lifestyles, proximity to amenities, and perceived convenience.
In seeking to address this gap, this study uses responses from a large-scale online survey undertaken in Calgary, Alberta to develop a population stratification through factor-cluster analysis to identify typologies of travel behavior, lifestyles, and perceptions of convenience. These typologies are then analyzed further to examine how perceived convenience varies between the groups, while additionally considering actual network distances to reach essential amenities based on the reported home locations. By contrasting perceived convenience of access to amenities between our travel behavior typologies and considering actual network distances to these amenities, our study sheds light on how to foster

\footnotetext{
'TransLink, Vancouver, Canada

${ }^{2}$ Department of Civil, Geological and Mining Engineering, Polytechnique Montréal, Montréal, Canada

${ }^{3}$ School of Urban Planning, McGill University, Montréal, Canada

Corresponding Author:

Address correspondence to Ahmed El-Geneidy: ahmed.elgeneidy@mcgill.ca
} 
greater perceived convenience through transport, land use, and potentially housing interventions. This study therefore has a potential to assist researchers and planners concerned with increasing perceived convenience of reaching destinations by sustainable modes, amongst key segments of the population, and can assist in developing appropriate policies for these segments.

\section{Literature Review}

\section{Determinants of Perceived Convenience}

Previous studies have explored the factors that affect how individuals perceive the convenience of trips, in an effort to identify how policies and interventions can support the use of sustainable transport. Time-efficiency, cost, and trip distance appear to be major determinants of perceived convenience (4). In this regard, previous research found that car users and suburban residents typically find driving more convenient $(1,2,5)$, whereas dense, mixed-used areas with limited and expensive parking are typically more convenient for walking and cycling (1).

Research has also shown that convenience is a multifaceted concept which is affected by a diversity of utilitarian and non-utilitarian factors, and which varies according to individuals' preferences, trip purpose, and conditions $(4,6)$. Through an analysis of 24 in-depth interviews, Buys and Miller (4) demonstrated that the perceived convenience of different travel modes is closely related to non-utilitarian aspects such as attitudinal, affective, and symbolic aspects, in addition to utilitarian factors such as time-efficiency consideration. For example, the interviews revealed that the symbolism of the car led some participants to find it more convenient, while others found walking and cycling more convenient or attractive for health or sustainability reasons. Similarly, previous research has highlighted the importance of affective and attitudinal factors in determining satisfaction with trips and mode choice $(2,6)$. According to Johansson, Heldt, and Johansson (6) personality traits are revealed by mode choice, but also by "other actions of their everyday life," which we refer to in this study as lifestyle. The importance of trip convenience in selecting a mode also varies widely across individuals and contexts. For example, Johansson, Heldt, and Johansson (6) found that higher-income individuals attached more importance to trip convenience compared with lowincome individuals. Anable and Gatersleben (2) showed that respondents value convenience more in relation to work trips than to leisure trips. This further highlights the complexity of understanding how convenience is perceived by different individuals.

One key study to build on within this analysis is that of Krizek, Horning, and El-Geneidy (7), who sought to ascertain how perceptions of proximity to local services varied across different sociodemographic/socioeconomic groups and physically active/inactive residents of Minnesota. This study found that perceived walking distance varies based on the characteristics of an individual's neighborhood and the type of destination being judged. We therefore aim to account for a variety of local amenities within our study and additionally account for what amenities were important to individuals at the time they chose their current home location.

\section{Segmentation Approaches}

Research on travel behavior has shown there are statistically significant differences in perceptions of convenience and accessibility structure, depending on trip purposes and household profiles (3). Many studies have therefore used population or market segmentation techniques to stratify survey respondents into typologies of cyclists, public transport riders, pedestrians, and other travel behavior groupings to determine how key groups of people behave, perceive their environment, or would likely respond to a proposed policy $(8-11)$. Focusing on one mode, van Lierop and El-Geneidy (9) used a cluster analysis approach to separate public transport riders into typologies beyond the common captive- and choice-rider model, and developed nine distinct typologies, which offered greater detail for public transport promotion policy. Comparable studies were undertaken for urban cyclists, with the aim to explore both the motivations to cycle and differing preferences for cycling infrastructure among segments of the cycling population $(8,12)$.

Other segmentation studies have looked at travel behavior for the full range of different mode users. Previous research focusing on environmental impacts of private car trips used three driver typologies and three public-transport-rider/cyclist typologies based on travel behavior to explore car ownership preferences between groups (13). Another study looking at motivations and preferences for commuting and leisure trips segmented car-drivers, cyclists and those who walk, according to preferences, worldviews, and attitudes (14). These studies contribute to better understanding travel behavior across mode users. However, none of these studies have looked specifically into convenience and distance across a wide range of travel behavior typologies.

Segmentation approaches have found that typologies including attitudes and lifestyles, in addition to travel behavior, have the potential to reveal varying and unexpected levels of satisfaction and responses $(10,14)$. Population- and market-segmentation-based research can therefore provide insights into travel behavior that would otherwise be lost when looking at more aggregated analyses of travel behavior surveys. 


\section{Data}

\section{Study Context}

Calgary's total population in 2015 was 1.4 million (15). Calgary's motor-vehicle transportation network is served by an extensive "Ring Road" highway system that circumnavigates the city, with the Dearfoot Trail, Crowchild Trail, and Stoney Trail highways connecting to central Calgary. Additionally, the city is served by light-rail and an extensive bus system. For walking and cycling, Calgary has an extensive pathway network, a growing network of on-street cycling infrastructure, and a physically separated cycle-track network in the city's downtown. Though Calgary has made significant progress with utilitarian cycling infrastructure, direct connections to important destinations in the peripheral areas of the city remain to be developed in some areas. Calgary's employment areas are largely concentrated in downtown with increasing residential density in downtown, especially in the developing East Village neighborhood. However, many Calgary residents live in more suburban contexts, as the city's lack of geographic barriers has supported sprawling development.

\section{Calgary Liveability Survey}

The survey data used within this study was collected using an online platform (LimeSurvey) and was promoted through various online venues relevant to residents of Calgary. Numerous community associations, recreational groups, schools, and other groups based in Calgary were asked to circulate a descriptive and promotional email to their membership. Furthermore, links to the survey were circulated in social media and posts were made on online forums for Calgary interest groups. Draw prizes were offered as incentives to participate. The survey was collected in collaboration with the City of Calgary as part of a liveability study. The data collection period ran for 28 days, from February 2 to March 2, 2017. In total, 1,873 responses were collected, which includes respondents who opened the survey, but did not start the survey. 1,524 partial and complete survey responses were collected, out of which 1,061 respondents progressed to the last page of the survey. Because of the detailed travel behavior, socioeconomic, and origindestination information collected in this survey, many questions were made optional for privacy reasons. 711 respondents were used in this study, who answered all mandatory and optional questions that were chosen as inputs for the cluster analysis.

Respondents were asked to locate several key travel destinations such as their home, work/school, preferred grocery store, and most frequently visited park by placing a pin on a map. Respondents were also asked to rank several factors in order of importance when considering their home location, such as proximity to local amenities, neighborhood characteristics, and property aspects. Additionally, the survey asked detailed mode choice and ordinal-ranked travel convenience questions for a variety of trip types, including work, groceries, recreation, needs of children, and cultural/entertainment destinations. Further details were gained about these trip types in various weather conditions. The survey also included many optional socioeconomic and household structure questions, which collected information on aspects such as education level, income, number of children in the household, number of cars owned by the household, and age of the respondent.

\section{Convenience of Access to Essential Amenities}

To collect information about perceptions of how convenient it is for Calgarians to reach a selection of essential amenities, several survey questions were asked using an ordinal-ranked selection, with the options: Extremely Convenient (5), Somewhat Convenient (4), Neutral (3), Somewhat Inconvenient (2), Extremely Inconvenient (1), and Not Applicable. The questions included locations such as work/post-secondary school, grocery stores, children's school/preschool, bus stops, and cultural and entertainment attractions. Additionally, these questions were asked for both warm/dry and cold/wet conditions. For this study, the convenience of access for warm/dry and cold/wet conditions were averaged for each survey respondent, to create one, aggregated convenience of access variable.

\section{Home Location Network Distance to Amenities}

Using respondents' home locations, we measured network distances to amenities in our study using GIS to calculate the shortest network distance to several destinations for each survey participant. The purpose of developing this variable was to help understand home choice decisions based on proximity to points of interest in Calgary. This analysis did not attempt to model routes based on known mode choices from the survey.

When locations were provided, the shortest network distances to respondents' specified work, school, preferred grocery store, and preferred park locations were calculated. Additionally, the network distance from each home location to the nearest bus stop, light-rail transit (LRT) stop, and schools (of all levels) were calculated. The City of Calgary's GIS business license data was used to separate business locations into Entertainment and Goods/Services categories; the network distances to the nearest five entertainment destinations and the nearest five goods/services destinations were also calculated for 


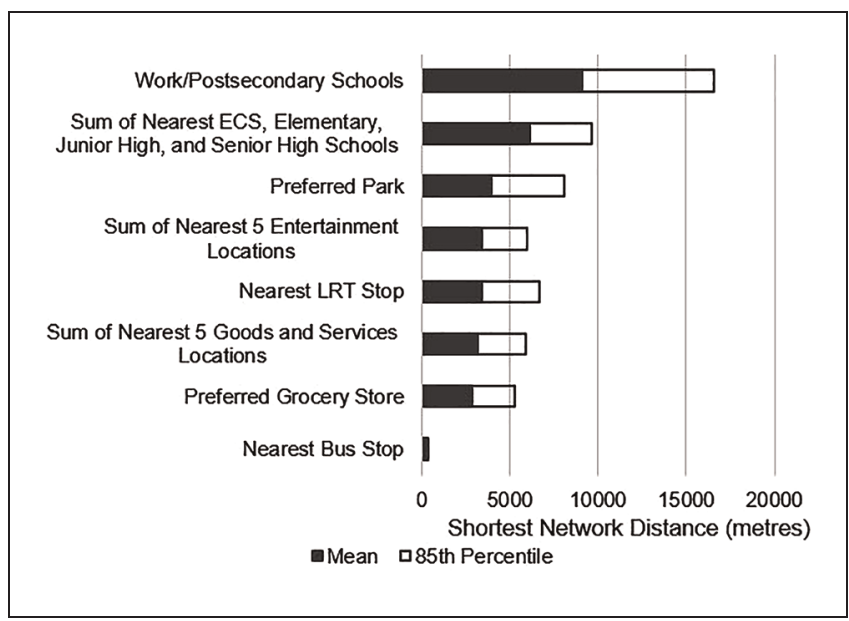

Figure I. Average network distances to essential amenities from home locations.

each survey respondent. Figure 1 shows the average distance and the 85th percentile distances to the aforementioned amenities for the home locations of all respondents.

\section{Analysis}

\section{Principle Component Factor Analysis}

We conducted a principal component analysis (PCA) of all questions in the survey relevant to travel behavior and perceptions. PCA groups correlated variables into factors that can explain the variability in the data. The created factors become a new set of linearly uncorrelated variables, helping to reduce the number of variables in the analysis (16). Varimax rotation, which maximizes the sum of the variances of the squared loadings, was used to identify survey questions with more correlated factor loadings. Variables with the least correlated factor loadings were iteratively removed from the PCA in order of their non-significance, which led to a set of factors with factor loadings all above 0.5 or below -0.5 . Table 1 shows the grouped survey question variables, their factor loadings, and assigned factor names.

\section{K-Means Cluster Analysis}

The second step was to use the 14 PCA factors in a $k$ means cluster analysis to identify different groups of travelers. This two-step, factor-cluster process, has been shown to effectively segment survey responses into thematic groupings (clusters) of common trends within the PCA factors $(8,9,17)$. In this study, the generated factor scores for each variable used in the PCA factors were used to identify groups of respondents with similar travel behavior, experiences, and perceptions. By minimizing the intragroup differences, while maximizing intergroup differences between clusters, the cluster analysis highlights common themes in the survey findings. Whereas many other studies on market segmentation are more focused, such as cyclist or public transport rider specific studies, this study attempted to categorize a full range of individual travel behavior typologies. This broader scope led to an eight-cluster stratification used for the analysis, which is described in detail in our results section.

Figure 2 shows the eight clusters of travel behavior, experiences, and perceptions in Calgary, with the cluster typology names displayed above. Additionally, each cluster's proportion of representation in the sample is listed below the names. The plotted cluster centers represent the relative predominance of the 14 factors in segmenting the clusters. Positive values indicate a positive association with the cluster and negative values indicate a negative association. For example, in the first group, the factor named "Proportion of Trips Taken by Bicycle" is highly associated with this first group, in a positive direction: this suggests the group is predominantly defined by their high number of cycling trips. Factors with both negative and positive factor loadings represent cases where included variables are correlated, but in opposite directions. For example, when positive, the factor named "Car Ownership (+ ), Transit Ridership (-)" indicates high rates of possessing a driver's license and having access to a car, but a low proportion of trips taken by public transport.

\section{Results}

The eight-clusters and the identified travel typologies were used to extract summary statistics and data specific to each group. Eight, one-page "data compositions" were generated for each group which summarizes information unique to each group, namely the average travel distance to various amenities. The data compositions help to further understand the lifestyle, sociodemographic, and spatial differences between the eight traveler typologies and are provided in Figures 3-10. The main results are presented below, by traveler typologies.

\section{Committed Cyclists (Figure 3)}

Committed cyclists $(6.3 \%$ of the sample) are primarily unique because of their all-trip mode share, which is dominated by bicycle trips. This group tends to live in amenity-rich environments, as network distances to essential amenities are generally far below average. Committed cyclists also tend to rate their convenience to reach essential amenities above average and "presence of nearby amenities" emerges as the group's top home location consideration. Further highlighting their interest 
Table I. PCA Factor Loadings

\begin{tabular}{|c|c|c|c|c|}
\hline Factor name & Question/variable & Sub questions/variable & Conditions & Factor loading \\
\hline \multirow[t]{8}{*}{$\begin{array}{l}\text { Satisfaction with } \\
\text { grocery trips }\end{array}$} & $\begin{array}{l}\text { Please rate your level of } \\
\text { agreement with the following } \\
\text { statements about your trip to } \\
\text { your preferred grocery store }\end{array}$ & $\begin{array}{l}\text { I am satisfied with the travel } \\
\text { time of my trip }\end{array}$ & Cold, Wet & .861 \\
\hline & & $\begin{array}{l}\text { I am satisfied with the travel } \\
\text { time of my trip }\end{array}$ & Warm, Dry & .852 \\
\hline & & $\begin{array}{l}\text { Overall, I am satisfied with my } \\
\text { trip }\end{array}$ & Warm, Dry & .840 \\
\hline & & $\begin{array}{l}\text { Overall, I am satisfied with my } \\
\text { trip }\end{array}$ & Cold, Wet & .839 \\
\hline & & $\begin{array}{l}\text { The cost of my trip is } \\
\text { reasonable }\end{array}$ & Cold, Wet & .838 \\
\hline & & $\begin{array}{l}\text { The cost of my trip is } \\
\text { reasonable }\end{array}$ & Warm, Dry & .837 \\
\hline & & $\begin{array}{l}\text { The travel time of my trip is } \\
\text { consistent }\end{array}$ & Warm, Dry & .798 \\
\hline & & $\begin{array}{l}\text { The travel time of my trip is } \\
\text { consistent }\end{array}$ & Cold, Wet & .775 \\
\hline \multirow[t]{6}{*}{$\begin{array}{l}\text { Convenience } \\
\text { to Reach } \\
\text { Entertainment }\end{array}$} & $\begin{array}{l}\text { How convenient is it for you to } \\
\text { reach the following } \\
\text { destinations? }\end{array}$ & $\begin{array}{l}\text { Retail options (clothing stores, } \\
\text { book stores, etc.) }\end{array}$ & Cold, Wet & .852 \\
\hline & & $\begin{array}{l}\text { Cultural and entertainment } \\
\text { attractions }\end{array}$ & Cold, Wet & .834 \\
\hline & & $\begin{array}{l}\text { Retail options (clothing stores, } \\
\text { book stores, etc.) }\end{array}$ & Warm, Dry & .824 \\
\hline & & $\begin{array}{l}\text { Cultural and entertainment } \\
\text { attractions }\end{array}$ & Warm, Dry & .815 \\
\hline & & $\begin{array}{l}\text { Recreational locations (gyms, } \\
\text { community center, etc.) }\end{array}$ & Cold, Wet & .791 \\
\hline & & $\begin{array}{l}\text { Recreational locations (gyms, } \\
\text { community center, etc.) }\end{array}$ & Warm, Dry & .773 \\
\hline \multirow{5}{*}{$\begin{array}{l}\text { Distance to } \\
\text { CBD (-) and } \\
\text { Proportion of } \\
\text { Trips Taken by } \\
\text { Walking }(+) \\
\text { and Driving }(-)\end{array}$} & $\begin{array}{l}\text { Recoded variable of mode } \\
\text { choice questions for all } \\
\text { destinations }\end{array}$ & $\begin{array}{l}\text { Proportion of all trips, mode } \\
\text { choice: walk }\end{array}$ & Cold, Wet & .886 \\
\hline & & $\begin{array}{l}\text { Proportion of all trips, mode } \\
\text { choice: walk }\end{array}$ & Warm, Dry & .865 \\
\hline & & $\begin{array}{l}\text { Proportion of all trips, mode } \\
\text { choice: drive }\end{array}$ & Warm, Dry & -.734 \\
\hline & & $\begin{array}{l}\text { Proportion of all trips, mode } \\
\text { choice: drive }\end{array}$ & Cold, Wet & -.733 \\
\hline & Created variable & Network distance to CBD fror & ported home location & -.565 \\
\hline \multirow[t]{4}{*}{$\begin{array}{l}\text { Convenience to } \\
\text { Reach Transit }\end{array}$} & $\begin{array}{l}\text { How convenient is it for you to } \\
\text { reach the following } \\
\text { destinations }\end{array}$ & Bus stops & Warm, Dry & .787 \\
\hline & & Bus stops & Cold, Wet & .781 \\
\hline & $\begin{array}{l}\text { How convenient is it for you to } \\
\text { reach the following } \\
\text { destinations }\end{array}$ & LRT stops & Warm, Dry & .756 \\
\hline & & LRT stops & Cold, Wet & .745 \\
\hline \multirow[t]{2}{*}{$\begin{array}{l}\text { Liveable } \\
\text { Neighborhood }\end{array}$} & $\begin{array}{l}\text { Please rate how easy it is for } \\
\text { you to travel by the following } \\
\text { modes of transportation in } \\
\text { your neighborhood }\end{array}$ & Cycling & & .749 \\
\hline & & Walking & & .729 \\
\hline
\end{tabular}


Table I. (continued)

\begin{tabular}{|c|c|c|c|c|}
\hline Factor name & Question/variable & Sub questions/variable & Conditions & Factor loading \\
\hline & $\begin{array}{l}\text { How would you rate the overall } \\
\text { liveability of your } \\
\text { neighborhood (ability to } \\
\text { access your essential } \\
\text { amenities) }\end{array}$ & & Warm, Dry & .633 \\
\hline & & & Cold, Wet & .616 \\
\hline \multirow{4}{*}{$\begin{array}{l}\text { Car Ownership } \\
(+), \text { Transit } \\
\text { Ridership }(-)\end{array}$} & $\begin{array}{l}\text { Select all the following that } \\
\text { apply to you }\end{array}$ & I have a driver's license & & .735 \\
\hline & & \multicolumn{2}{|c|}{ I have access to a privately-owned car (not carshare) } & .706 \\
\hline & $\begin{array}{l}\text { Recoded variable of mode } \\
\text { choice questions for all } \\
\text { destinations }\end{array}$ & $\begin{array}{l}\text { Proportion of all trips, mode } \\
\text { choice: transit }\end{array}$ & Cold, Wet & -.637 \\
\hline & & $\begin{array}{l}\text { Proportion of all trips, mode } \\
\text { choice: transit }\end{array}$ & Warm, Dry & -.633 \\
\hline \multirow[t]{2}{*}{$\begin{array}{l}\text { Proportion Trips } \\
\text { Taken by Bicycle }\end{array}$} & $\begin{array}{l}\text { Recoded variable of mode } \\
\text { choice questions for all } \\
\text { destinations }\end{array}$ & $\begin{array}{l}\text { Proportion of all trips, mode } \\
\text { choice: bike }\end{array}$ & Cold, Wet & .899 \\
\hline & & $\begin{array}{l}\text { Proportion of all trips, mode } \\
\text { choice: bike }\end{array}$ & Warm, Dry & .893 \\
\hline \multirow[t]{2}{*}{$\begin{array}{l}\text { Occupation: } \\
\text { Employed }(+) \\
\text { Student }(-)\end{array}$} & $\begin{array}{l}\text { What describes you best? } \\
\text { (Please choose the option } \\
\text { applies to you the most) }\end{array}$ & Student & & -.907 \\
\hline & & Employed & & .900 \\
\hline Transit Enjoyment & $\begin{array}{l}\text { How much do you agree with } \\
\text { the following statements? }\end{array}$ & I enjoy riding the LRT & & .857 \\
\hline $\begin{array}{l}\text { Home Choice: } \\
\text { Importance of } \\
\text { Transport } \\
\text { Network/Systems }\end{array}$ & $\begin{array}{l}\text { When choosing your current } \\
\text { home location, please rank at } \\
\text { least the top three factors in } \\
\text { order of importance to you } \\
\text { and others living in the home: }\end{array}$ & $\begin{array}{l}\text { I enjoy riding the bus } \\
\text { Top choice: quality of the tran }\end{array}$ & tation network/systems & $\begin{array}{l}.849 \\
.881\end{array}$ \\
\hline \multirow{2}{*}{$\begin{array}{l}\text { Age and Years } \\
\text { Spent at Current } \\
\text { Home Location }\end{array}$} & What year were you born? & Recoded variable for age (year & & .848 \\
\hline & $\begin{array}{l}\text { In what year did you start living } \\
\text { in your current residence? }\end{array}$ & $\begin{array}{l}\text { Recoded variable for years } \\
\text { spent in home }\end{array}$ & & .833 \\
\hline \multirow{2}{*}{$\begin{array}{l}\text { Importance of } \\
\text { Health and } \\
\text { Enjoyment When } \\
\text { Planning Trips }\end{array}$} & $\begin{array}{l}\text { How important are the } \\
\text { following statements when } \\
\text { planning any trip? }\end{array}$ & $\begin{array}{l}\text { The overall enjoyment of the } \\
\text { trip }\end{array}$ & & .725 \\
\hline & & $\begin{array}{l}\text { The long-term effect on my } \\
\text { health }\end{array}$ & & .723 \\
\hline $\begin{array}{l}\text { Home Choice: } \\
\text { Quality of the } \\
\text { Property }(+) \text {, } \\
\text { Presence of } \\
\text { Nearby } \\
\text { Amenities } \\
\text { Property (-) }\end{array}$ & $\begin{array}{l}\text { When choosing your current } \\
\text { home location, please rank at } \\
\text { least the top three factors in } \\
\text { order of importance to you } \\
\text { and others living in the home: }\end{array}$ & $\begin{array}{l}\text { The presence of nearby } \\
\text { amenities }\end{array}$ & & -.873 \\
\hline $\begin{array}{l}\text { Home Choice: } \\
\text { Character of the } \\
\text { Neighborhood }\end{array}$ & $\begin{array}{l}\text { When choosing your current } \\
\text { home location, please rank at } \\
\text { least the top three factors in } \\
\text { order of importance to you } \\
\text { and others living in the home: }\end{array}$ & $\begin{array}{l}\text { The quality of the property } \\
\text { The character of the } \\
\text { neighborhood }\end{array}$ & & $\begin{array}{l}.744 \\
.946\end{array}$ \\
\hline
\end{tabular}




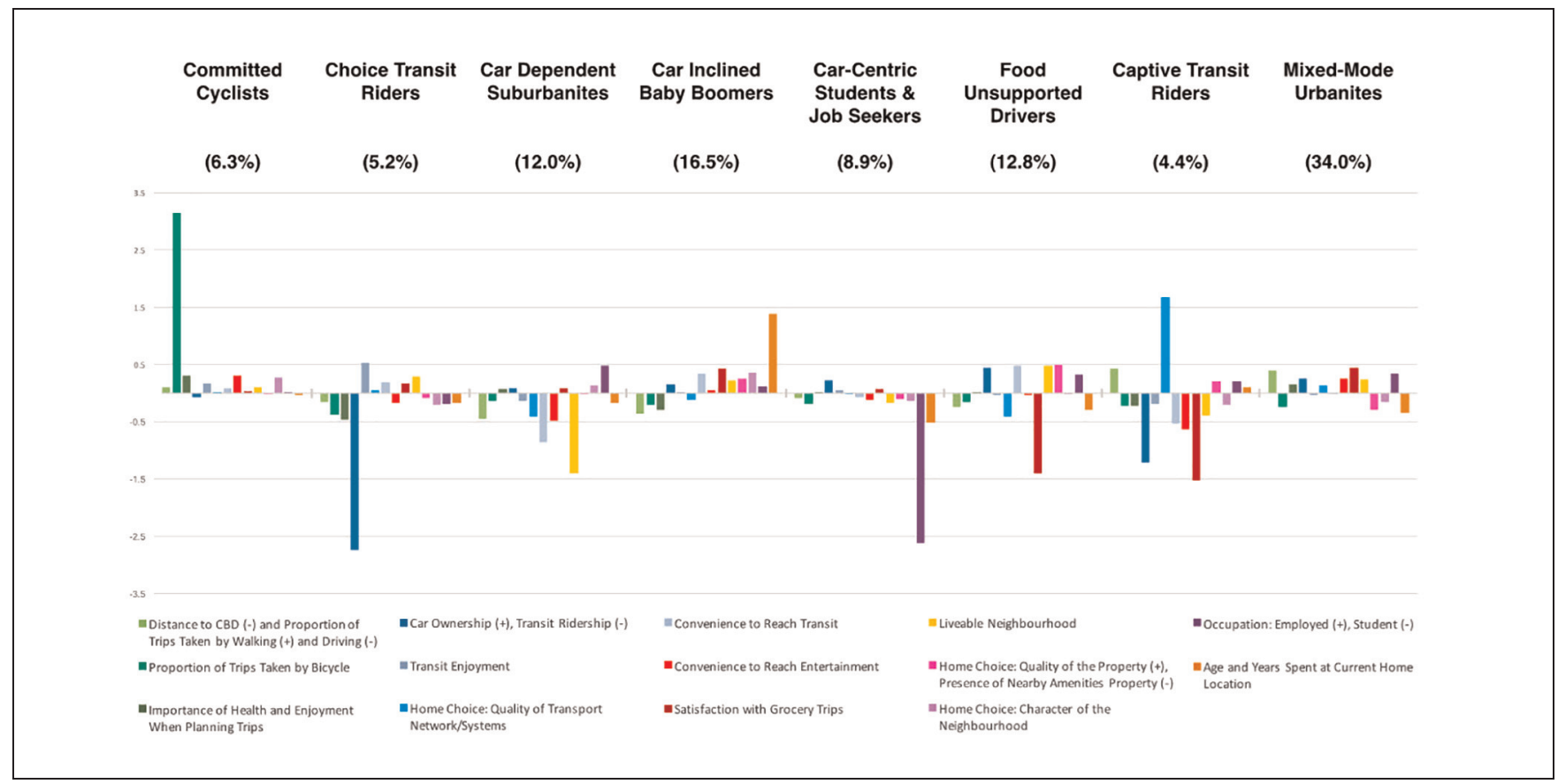

Figure 2. K-means travel behavior and liveability typology cluster center.

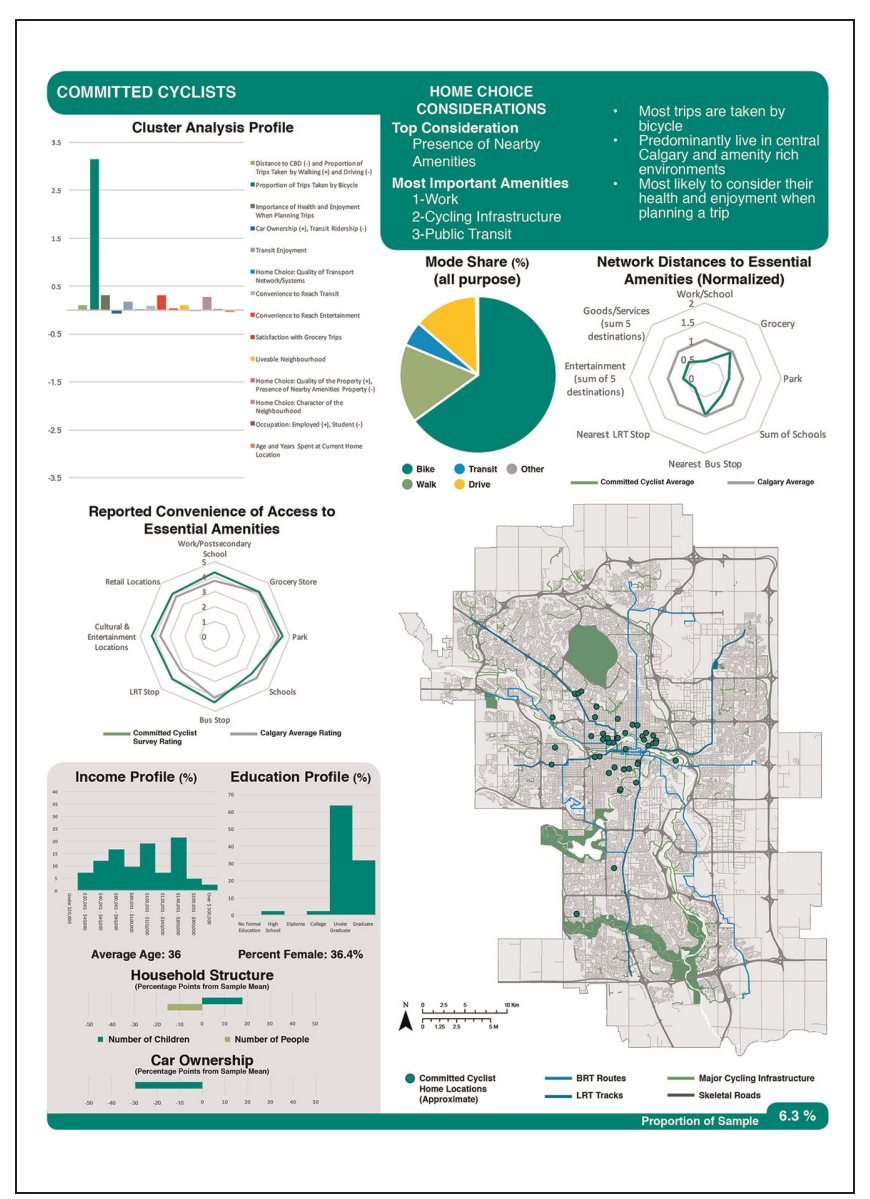

Figure 3. Data composition: committed cyclists. and reliance on cycling, the group's second highest rated amenity is access to cycling infrastructure, with work, and public transit access ranking as their second and third most important destinations. In line with expectations, committed cyclist home locations are tightly concentrated around central Calgary. Interestingly, committed cyclists are not particularly young on average (second highest average cluster age). They also have a slightly higher than average number of children, but also are highly educated with a mid to higher income profile. As expected, their car ownership rates are far below average.

\section{Choice Transit Riders (Figure 4)}

Choice transit riders $(5.2 \%$ of the sample) are primarily segmented from the rest of the sample by their very high transit ridership rates. The group also reports much higher levels of enjoyment when riding the bus or LRT than other groups and rates access to public transit as their most important proximate amenity when choosing a home location. With their enjoyment and prioritization of transit in their lifestyles, these individuals appear to be pro-transit, rather than "captive" transit riders (discussed below) $(9,18)$. Choice transit riders' top general consideration for home location is the presence of nearby amenities and they report living in more liveable, walkable, and bikeable communities. Despite prioritizing transit access in their home choice locations, choice transit riders travel further than average to reach LRT 


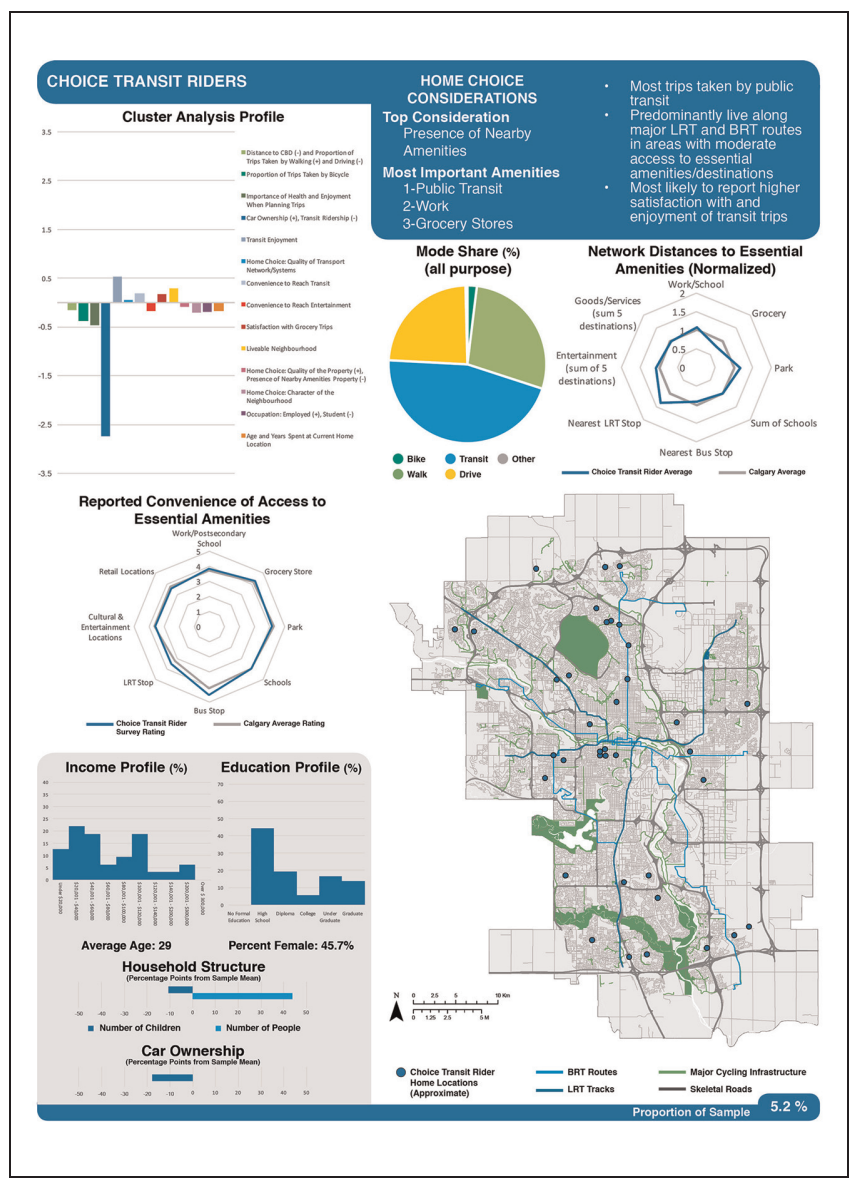

Figure 4. Data composition: choice transit riders.

stops but are closer than average to bus stops. As expected, many choice transit rider home locations are found along LRT and BRT routes. Choice transit riders are relatively young with a higher prevalence of students and have a slightly more modest income profile than other groups, accompanied by much lower car ownership rates.

\section{Car Dependent Suburbanites (Figure 5)}

Car dependent suburbanites (12.0\% of the sample) are primarily defined by their relatively low ratings of their neighborhood's liveability, walkability, and bikeability. They report low access to amenities in every category and in line with expectations, their reported amenityscarce environments are reflected in their network distances to essential amenities, which are often $50 \%$ to $100 \%$ above of the Calgary average. This suggests that they do not live in areas with strong land-use mix. Very few home locations are near central Calgary, with the majority located throughout peripheral neighborhoods. Unsurprisingly, their all-purpose mode share is car dominated. With their top housing choice priority

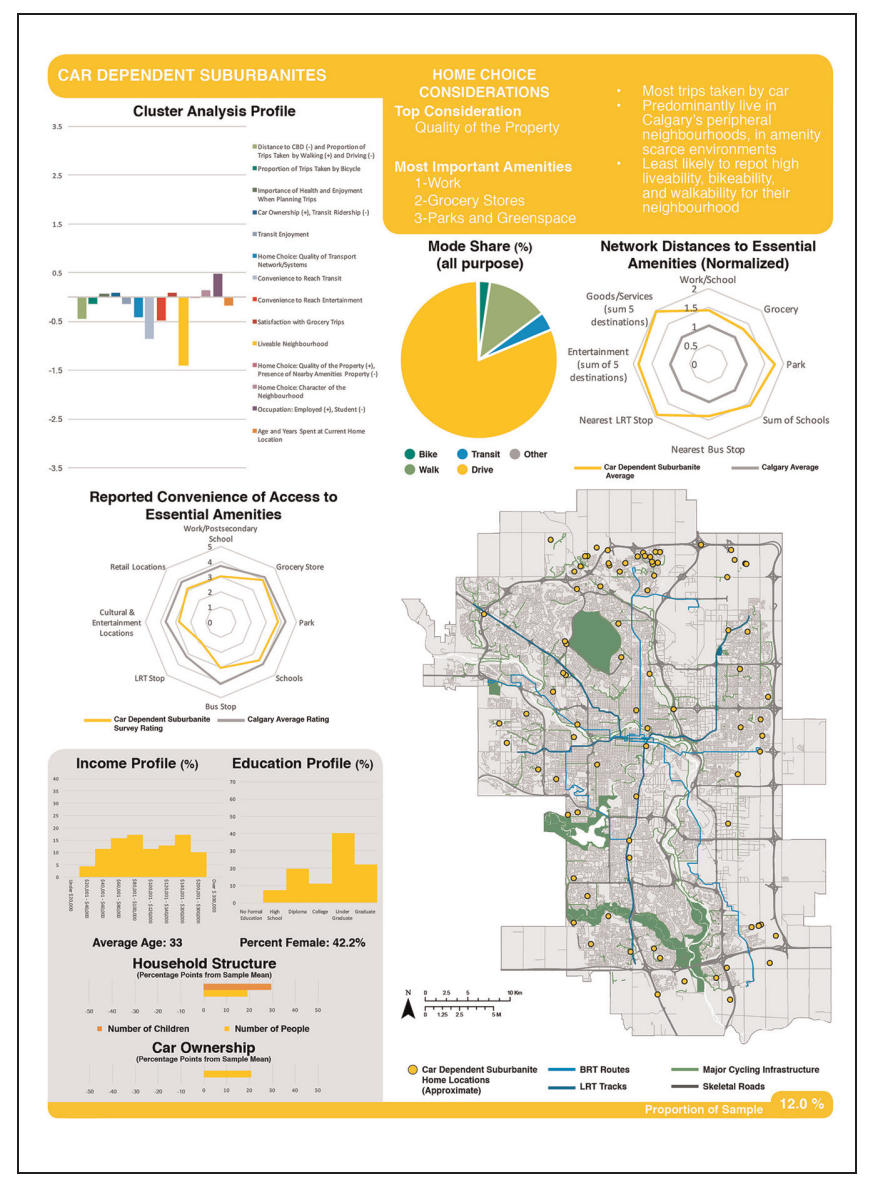

Figure 5. Data composition: car dependent suburbanites.

being the quality of the property, the group's car dependence is likely to be self-imposed. Highly educated and holding moderate to high incomes, car dependent suburbanites could likely afford to live in more amenity-rich environments but are choosing areas with more desirable properties. Despite work, grocery stores, and parks rated as their top ranked proximate amenities when choosing a home location, they do not appear to locate near these destinations. This group also has higher numbers of children and individuals in the household, suggesting that they are often part of larger families.

\section{Car Inclined Baby Boomers (Figure 6)}

Car inclined baby boomers (16.5\%) have the highest positive expression of the "Age and Years Spent at Current Home Location" factor, indicating they are older and have not moved recently. The group's average age of 50 years is much higher than other groups. Though the group's car-focused mode share is similar to the car dependent suburbanites' mode share, car inclined baby boomers rank their neighborhoods as more liveable, 


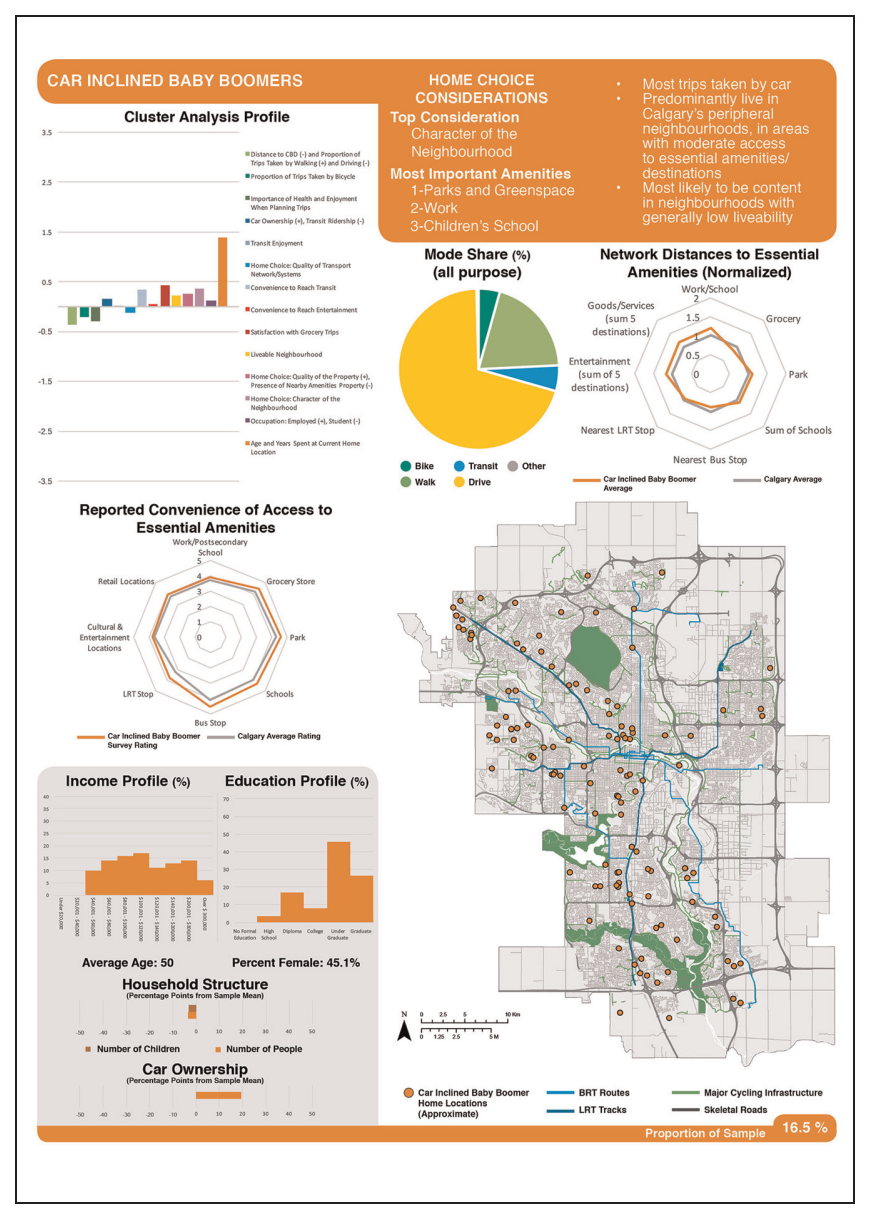

Figure 6. Data composition: car inclined baby boomers.

walkable, and bikeable. Compared with car dependent suburbanites, this group appears to be living in environments more befitting to their needs, with their network distances to essential amenities more in line with the Calgary average, yet this group still drives for the majority of their trips. They are represented throughout Calgary with less representation in the northeast. This group generally has the highest income of all the clusters and reside in small households with both numbers of children and individuals in the household below average. However, their second most important proximate amenity when choosing a home location is access to their child's school, suggesting cluster members are generally members of families whose children have left home. Despite lower numbers of people in the home, car inclined baby boomer households own more cars than the Calgary average.

\section{Car-Centric Students and Job Seekers (Figure 7)}

Car-centric students and job seekers (8.9\% of the sample) are primarily segmented from the rest of the sample by

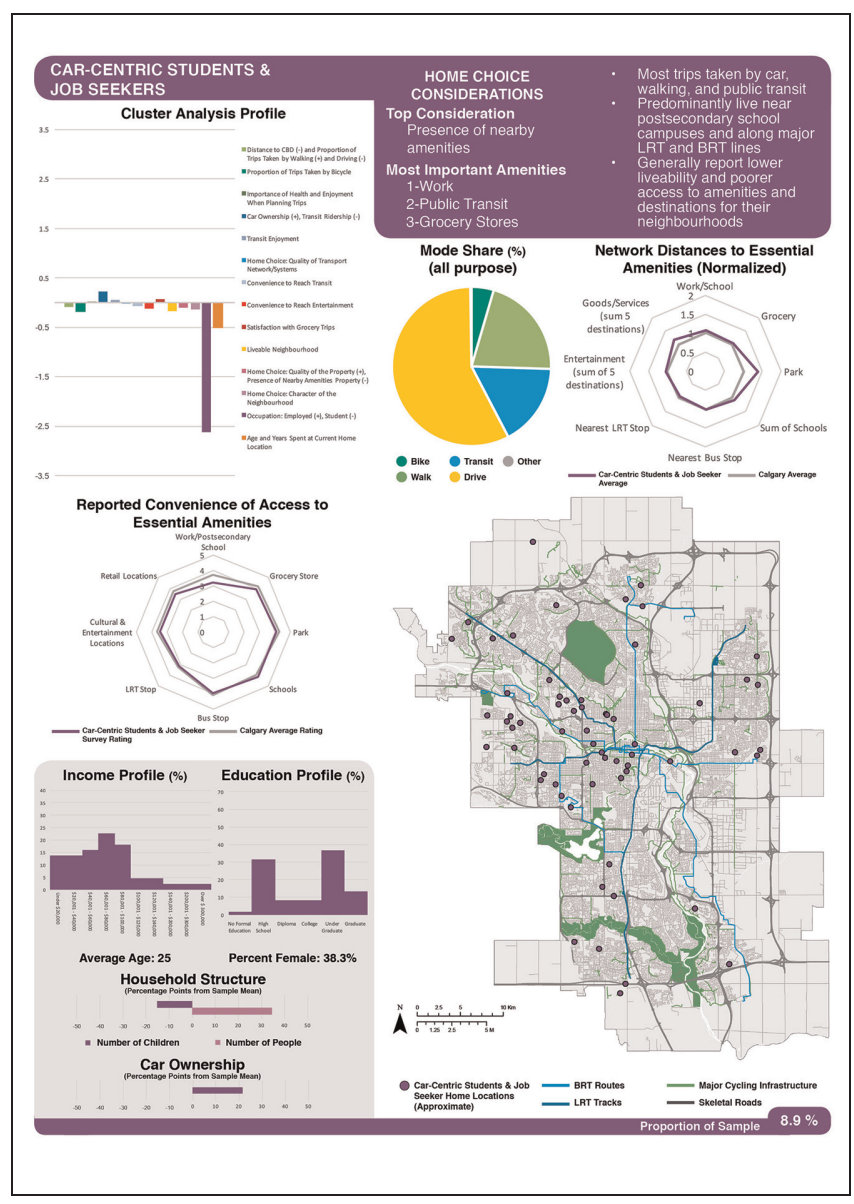

Figure 7. Data composition: car-centric students and job seekers.

their very low proportion of employed individuals and high proportion of students in the cluster. Geographically, they have a high representation proximate to the University of Calgary, Alberta College of Art and Design, and SAIT college campuses. This group has a much lower average age than other groups ( 25 years) and has not spent many years living in their current location. This group also has a modest income profile and fewer children, but higher numbers of individuals in the household than average, suggesting that they tend to live in larger households with roommates. Atypical of student populations, the car ownership rates of car-centric students and job seekers are above the Calgary average. With these aspects in mind, it seems there are also many individuals in this group that may be unemployed/underemployed and making travel choices similar to those of student populations. With Calgary's unemployment and office vacancy rates still recovering from the 2007 economic crash, it is not unexpected that some demonstrate regressive travel behaviors (19). When choosing a home location, their top 


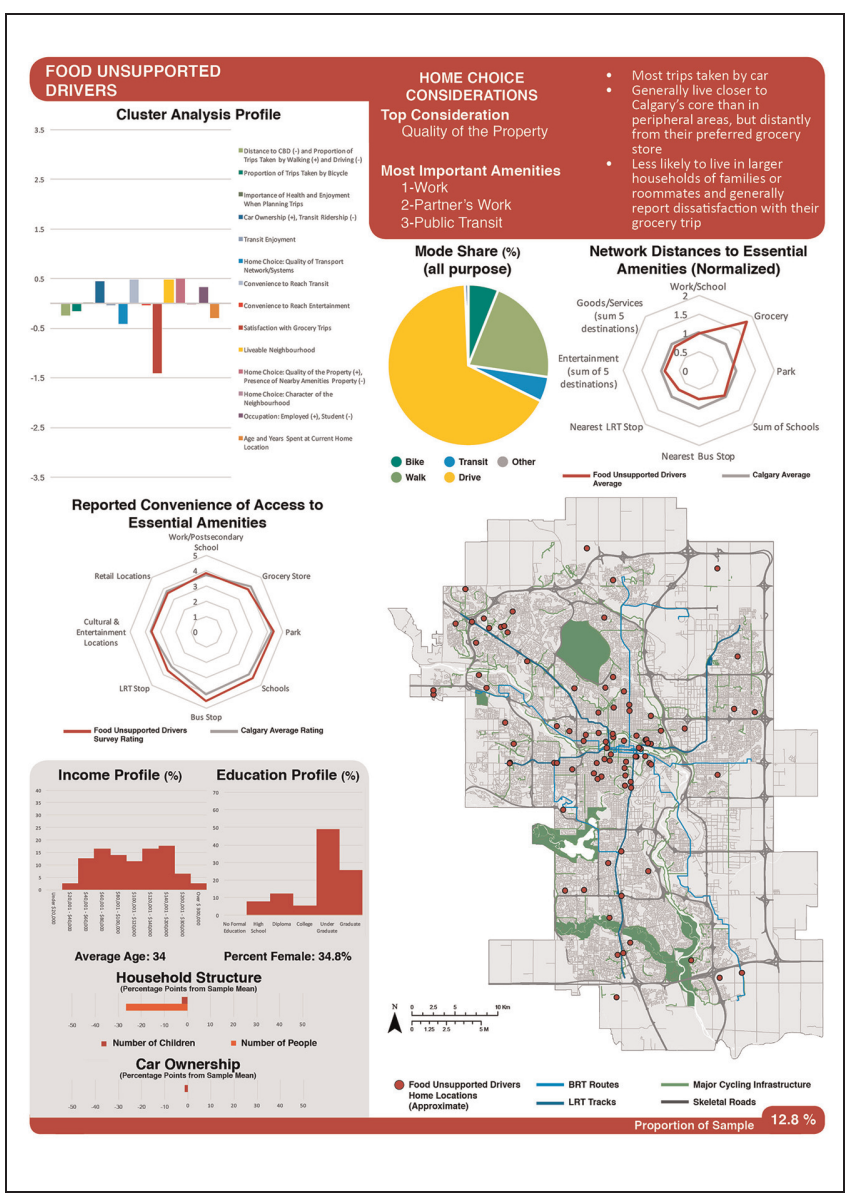

Figure 8. Data composition: food unsupported drivers.

consideration is the presence of nearby amenities and their rated convenience to reach these are also typically in line with the average. The group's network distances to essential amenities are generally in line with the average, but more distant for parks.

\section{Food Unsupported Drivers (Figure 8)}

Food unsupported drivers (12.8\% of the sample) are predominantly characterized by their strong dissatisfaction with the cost, time, and consistency of their grocery store trip. Cluster members of this group do not seem to fit the definitions of people living in food deserts (areas without access to retail food opportunities), or food mirages (lower-income areas, served by unaffordable, luxury grocers) (20). This suggests they may have relatively average access to grocery stores but choose to travel to more distant options. Food unsupported drivers, on average, travel almost twice the Calgary average distance to reach their grocery store and this group is largely car dominant in their all-purpose mode share. When choosing a home location, grocery store access is not highly prioritized by this group. One possible

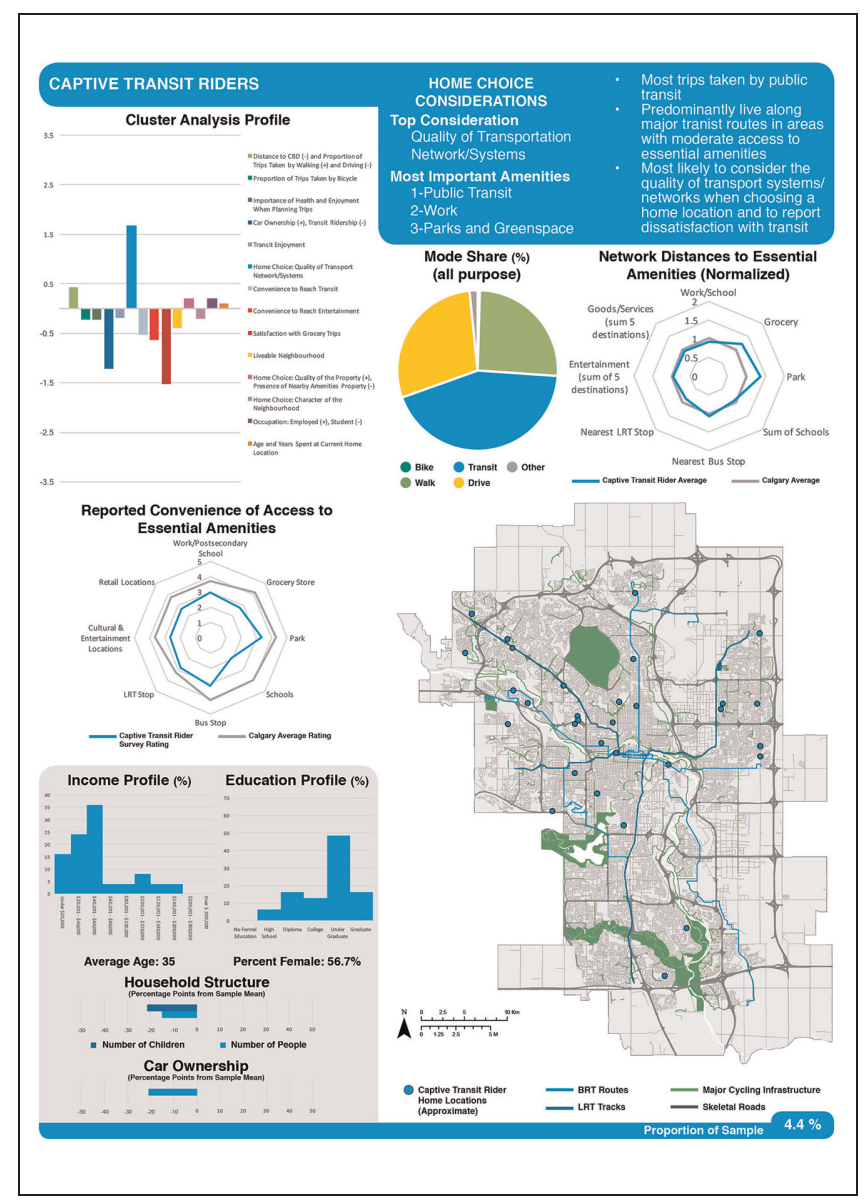

Figure 9. Data composition: captive transit riders.

explanation is that food unsupported drivers have specific dietary preferences (health food stores, ethnic specialty shops, etc.) or are loyal to specific stores (e.g., Costco). Such cultural preferences or brand loyalty could explain why food unsupported drivers are not utilizing more locally provided retail food opportunities. Yet, the current data does not allow for such conclusions and further data collection and analysis would be required to understand the long distances travelled to grocery stores by the members of this cluster. Food unsupported drivers have fewer children and total individuals in the home on average, suggesting cluster members are more likely to live alone or with a partner. Additionally, they are the only group to report their partner's work as an important proximate amenity when choosing a home location. Food unsupported drivers have a moderate to high income profile and are generally highly educated.

\section{Captive Transit Riders (Figure 9)}

Captive transit riders (4.4\% of the sample), like choice transit riders, demonstrate high transit ridership and low car ownership. However, unlike choice transit riders, 
captive transit riders report very low enjoyment when riding the bus or LRT; in fact, they have the second lowest rating of transit enjoyment of all the clusters, second only to car dependent suburbanites. With their dislike of, and high reliance on transit, captive transit riders also rate their neighborhood's liveability and access to a variety of amenities relatively lower than other groups. A further factor is that their top consideration when choosing a home location is the quality of the transport network/system. Furthermore, their average age is six years higher than the choice transit group and their incomes are lower, reaffirming a higher likelihood of being "stuck" in a transit-dependent lifestyle than having chosen one. This is in line with previous research on transit users segmentation (21). As expected, the home locations of captive transit riders tend to be along the LRT and bus rapid transit (BRT) routes in Calgary, predominantly in less central locations. Captive transit riders tend to have similar network distances to essential amenities to the Calgary average, although their rated convenience to reach essential destinations is lower than the Calgary average in every category. Importantly, although females represent less than $50 \%$ of the respondents in all other clusters (between $34.8 \%$ and $45.7 \%$ ), they represent $56.7 \%$ of the captive transit riders. This raises important questions from a gender equity standpoint, especially since this group is characterized by a low convenience of access. Further studies could build on the methodology presented here to conduct segmented analyses by gender and shed light on gender-specific issues and potential interventions.

\section{Mixed-Mode Urbanites (Figure 10)}

Mixed-mode urbanites (34.0\% of the sample) have the highest representation of Central Business District (CBD) based home locations and have the highest proportion of walking trips and the lowest level of driving trips. Based on their home location profile, they are also more focused on amenity than property quality when choosing home locations and are more satisfied than average with their trip to the grocery store. Their highest priority amenities to have nearby are work, grocery stores, and public transit stations. This group generally lives in amenity-rich environments, as their network distances to essential amenities are all below the Calgary average, whereas their rated convenience to reach essential amenities is above the Calgary average in every category. Their experienced easy access to essential amenities supports a more balanced mode share, with an exceptionally large proportion of walking trips. This group also has relatively high transit and cycling ridership. The group's homes are densely clustered around central Calgary. Mixed-mode urbanites are highly educated with a mid to higher income profile. Their car ownership rates are below the Calgary average.

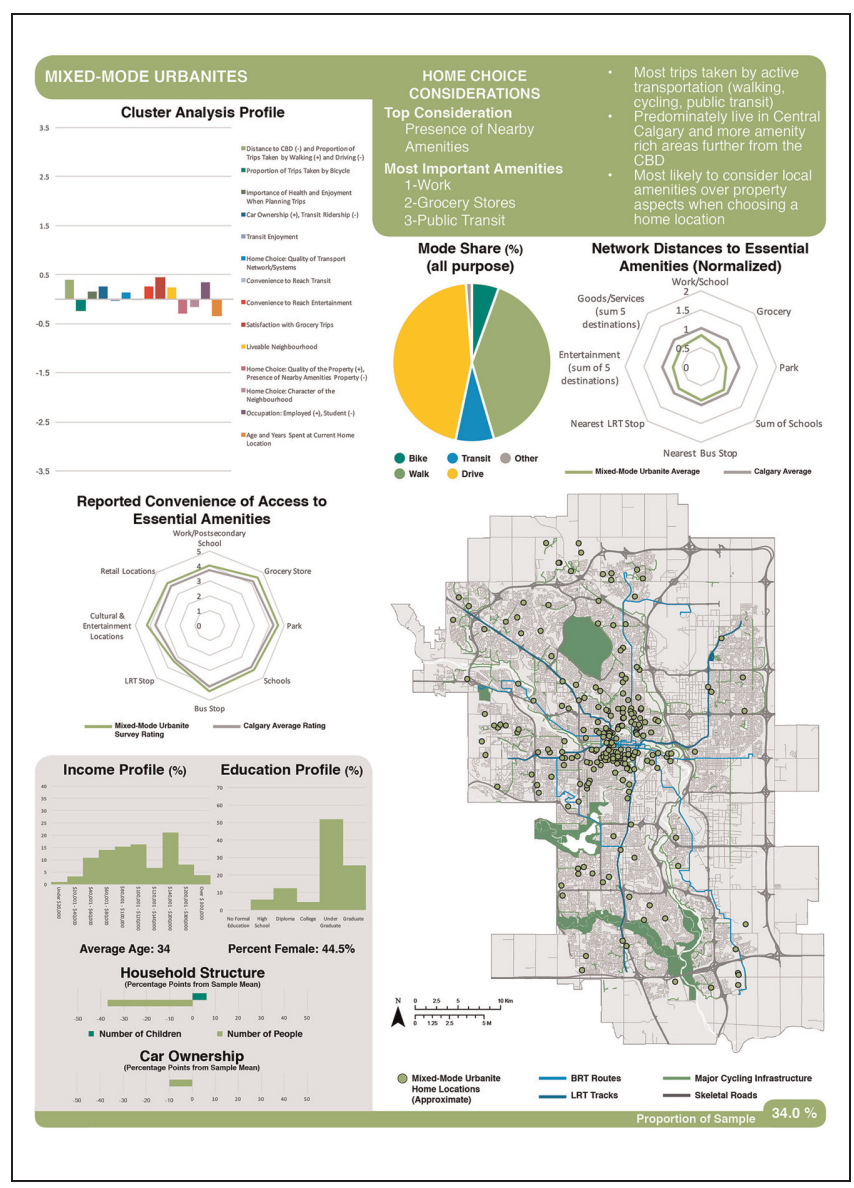

Figure 10. Data composition: mixed-mode urbanites.

\section{Discussion}

Summary graphs were used to further understand how reported convenience and actual distances vary between travel behavior typologies. Survey respondents provided pin-dropped locations for their work/postsecondary, preferred grocery store, and preferred park locations; these three amenities were chosen for further analysis. Figure 11 shows each cluster's proportion of individuals for each ordinal-ranked ratings of convenience of access to the three locations. The average network distance to the selected location is also indicated on a second axis.

\section{Options Matter}

Overall, we see that choice transit riders, committed cyclists, car inclined baby boomers, and mixed-mode urbanites tend to report higher convenience of access to work, grocery stores, and parks. Choice transit riders, committed cyclists, and mixed-mode urbanites clusters are characterized by housing locations in amenity-rich environments, and the presence of nearby amenities is important in the groups' home location choices. This 


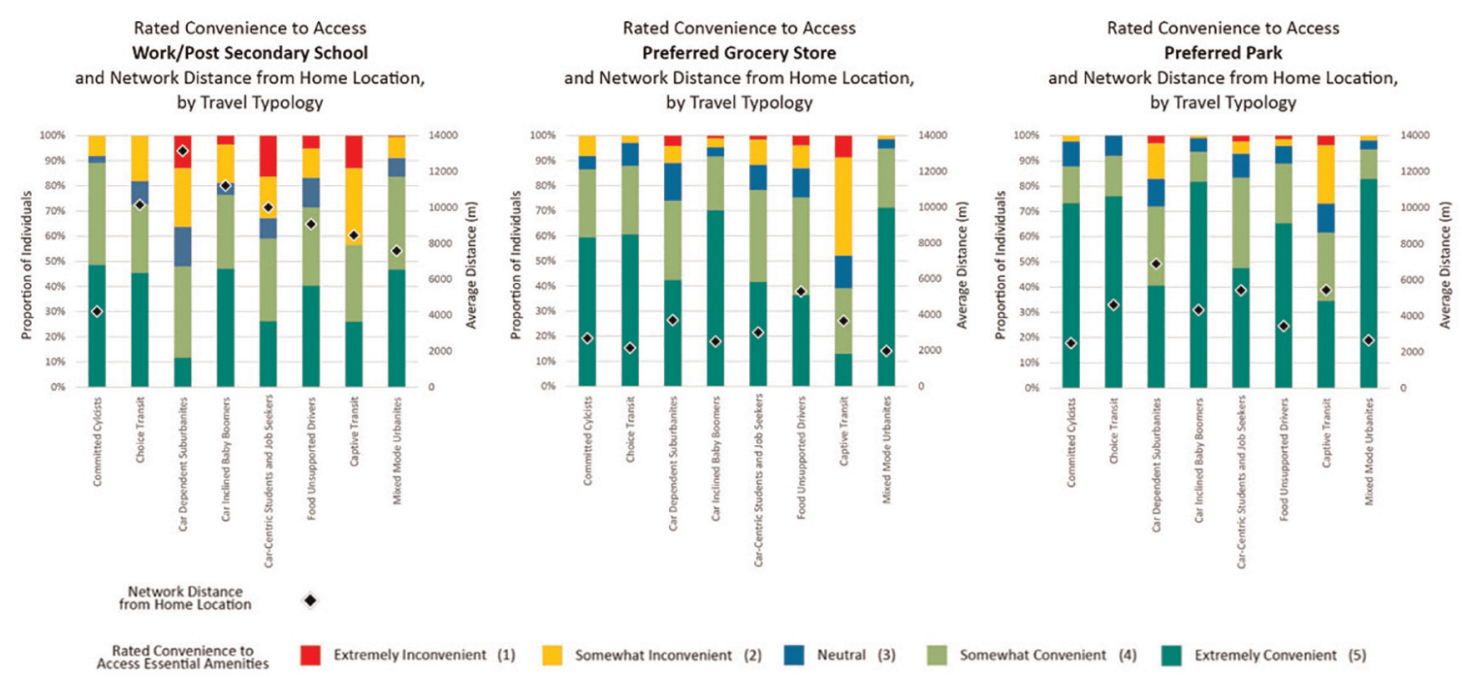

Figure I I. Rated convenience of access and average distance by cluster membership.

likely explains why they rate high convenience of access to essential amenities in their neighborhoods. Car inclined baby boomers also rate high convenience of access to the selected destinations, although the presence of nearby amenities is not their main concern. This suggests an important finding: whether it is by transit, by car, by cycling, or using a combination of modes, individuals that select their mode or home location by choice, rather than by constraint, find accessing destinations more convenient.

Conversely, captive transit users, car dependent suburbanites and car-centric students and job seekers typically exhibit higher proportions of individuals reporting low rates of convenience, compared with the other clusters. Individuals in these clusters typically live in amenityscarce neighborhoods and do not appear to be able to choose home locations according to their priorities. For example, car dependent suburbanites rate work, grocery stores, and parks as their most important proximate amenities, but do not live close to such amenities. In such contexts, the car is likely selected because of the lack of alternatives, as found in previous research (5). Similarly, captive transit riders report the quality of the transport system as their top priority when choosing their home location, but are not satisfied with their use of public transport. Buys and Miller (4) identified waiting time and unreliable service as disincentives for public transport use. Whereas choice riders have the option of using another mode if they find public transport unreliable or dislike waiting times (at different times of the day for example), captive riders are more likely to be forced to use public transport and tolerate disincentives. Previous research also found that higher-income individuals found trip convenience more important than lower-income individuals (6). This is consistent with our results, in which captive transit users and car-centric students and job seekers are characterized by lower incomes relative to other typologies. Those users likely select their modes because of financial or time constraints, rather than convenience considerations, which explains the lower rated convenience. Regarding car dependent suburbanites, who are not characterized by low income, other factors are to be considered. This typology is constrained by their decision to select more desirable proprieties, rather than amenity-rich neighborhoods.

Taken together, these findings demonstrate that individuals that are able to meet their travel or home location preferences are characterized by a higher perceived convenience of access to key destinations. From a policy perspective, having a set of alternatives is key to being able to select, at all times and for all trip purposes, an individual's preferred option. The importance of alternatives is highlighted in a previous study, which found that individuals that have alternative options to public transport find it more convenient if, for example, they can take a taxi if their bus does not arrive (4). Furthermore, previous studies found that the same individual might perceive the convenience of various modes differently depending on trip purpose or time of day. In other words, an individual will value different aspects depending on the destination or time of day. Conversely, the lack of public transport options is seen by car users as a major barrier to using public transport (5), which reinforces the importance of providing alternatives.

Another interesting finding from this study is that, among the clusters which are not considered constrained 
(choice transit riders, committed cyclists, mixed-mode urbanites, and car inclined baby boomers), those with higher sustainable mode shares (choice transit riders, committed cyclists, and mixed-mode urbanites) report higher convenience than the car-focused typology (car inclined baby boomers). Accordingly, whereas driving tends to be considered as the most convenient mode of transport by car users and suburban residents $(1,2,5)$, providing them with better sustainable options might increase their perceived convenience of travel. Furthermore, the results suggest that traveler typologies with walking- and cycling-focused mode shares (committed cyclists and mixed-mode urbanites) typically have a very low proportion of individuals reporting low convenience when taking into account all three destinations (work, grocery stores, and parks). Committed cyclists and mixed-mode urbanites typologies both rate their neighborhoods as generally more liveable and demonstrate that their amenity-rich environments support more sustainable travel behavior. The results of this study are, therefore, of useful consideration when planning for communities that are supportive of sustainable travel behavior.

\section{Distance Matters}

Looking at the average distance travelled by individuals in the different clusters (Figure 11), we observe that typologies that travel shorter average distances tend to have a higher proportion of individuals that report high convenience to access work, grocery stores, and parks. For example, we find that choice transit riders, committed cyclists, and mixed-mode urbanites tend to report higher convenience to access work, grocery stores, and parks, and they typically travel lower distances to these destinations. Committed cyclists travel shorter than average distances, which is consistent with the literature, suggesting that shorter distances are more convenient. Mixed-mode urbanites also tend to travel shorter distances than the other cluster groups, which might explain their higher rated convenience. Interestingly, we also see that perceived convenience to work is overall rated lower than other destinations. This contrasts with previous research, which found that convenience was a more important factor for work trips than leisure trips (2). However, our results demonstrate that distances to work are, on average, greater than distances to parks for example, supporting the influence of distance on perceived convenience. This could also be explained by the fact that leisure trips are less constrained in relation to time or schedule (4). Put together, these findings confirm that distance is a key component of convenience of access, as highlighted by Schneider (1).
However, there are some nuances to take into consideration. For example, choice transit riders travel, on average, longer distances to work than captive transit riders, and similar distances to parks, yet report higher convenience of access to these destinations. This is likely explained by a variety of factors: firstly, choice transit riders might benefit from more convenient transit trip in relation to schedules and service attributes (crowdedness, transfers, etc.). In this regard, Hine and Scott (5) found that captive riders were more likely to do multimodal trips. Secondly, it might be that having choices gives a better perception of convenience than being constrained, which reinforces the importance of alternatives. Thirdly, network distances might not reflect the actual time travelled by users, and choice riders might be able to use more efficient modes, which are characterized by longer distances, but shorter travel times.

\section{Conclusions}

Our results demonstrate that perceived convenience of accessing local amenities varies widely across the eight typologies and that these have profound implications for how land use and transport can support sustainable modes as well as higher perceived convenience of access for all individuals. Critically, the clusters are not merely characterized by their mode choice, but rather by many socioeconomic and lifestyle specific factors, which result in several categories of car-focused typologies and several typologies presenting very mixed modal splits.

Furthermore, our results illustrate how wider sample segregation across modes can produce valuable information regarding the perceived convenience of accessing local amenities. For this sample of residents of Calgary, we observe how distance correlates with reported convenience to work, grocery stores, and parks, but reported convenience is also closely related to modes available and options that meet the preferences of users, as well as to the possibility to locate according to preferences. Our analysis does not merely state that different mode users have differing levels of convenience, but also provides further detail on observed patterns of inter-mode segregation such as choice and captive transit riders, in addition to mixed-mode groups such as mixed-mode urbanites. Future research with larger samples sizes could build on this study to further explore the correlations between distances, mode choice, reported convenience, and lifestyle. Furthermore, building on the results of this study, structural equation modelling approaches could be adopted in future research to quantify the effect of various variables on convenience and mode choice.

We acknowledge some limitations of this study, such as the discrepancies between the mode share of survey respondents and the mode share of the general 
population in Calgary as reported in the 2011 Canadian Census results. The commute mode share from survey respondents seem to under-represent drivers (44\% compared with $74 \%$ ), while over-representing cyclists, pedestrians, and public transport riders. The mode share of survey respondents was more in line with the modal split of observations within the CBD Cordon Count undertaken by the City of Calgary (22), suggesting that the liveability survey received responses from a disproportionate number of people employed in the CBD. Alternatively, certain populations may be more eager to fill out online surveys about travel research, which could explain the over-representation of more urban-minded groups such as the committed cyclists and mixed-mode urbanites. Secondly, this study did not calculate closest network distances using the mode choice indicated by respondents, and instead calculated shortest distances with all routes of the road network available, which may not reflect the preferred routes of pedestrians, or the available pathways available to cyclists, or transit routes.

Nevertheless, the findings of this study are of value to researchers and planners concerned with land use and transport interventions and understanding what contributes to the perception of convenient access to local amenities. The travel typologies created within this study build on previous cases within the literature and incorporate many additional aspects such as priorities when selecting current home locations and perceptions of overall walkability and bikeability of the local built environment. These were found to contribute to our factorcluster analysis and are potentially valuable aspects to incorporate in future studies of travel behavior, preferences, and population segmentation approaches for transportation research and planning. The study can also inform land use and transport policy-making by revealing the importance of providing a variety of options in relation to modes and home locations to improve convenience and use of sustainable modes.

\section{Acknowledgments}

The authors would like to thank Greg McCarthy for his invaluable help in providing suggestions for key social media accounts, online forum pages, and specific contacts in Calgary for promoting the survey. Additionally, we would like to thank the many Twitter followers, Facebook groups, and forum members in Calgary who shared and promoted this survey, who are too numerous to list. This research was partially funded by the Natural Science and Engineering Research Council of Canada (NSERC) discovery grant.

\section{Author Contributions}

The authors confirm contribution to the paper as follows: study conception and design: MO, GB, AE-G; data collection: MO, AE-G; analysis and interpretation of results: $\mathrm{MO}, \mathrm{GB}, \mathrm{AE}-\mathrm{G}$; draft manuscript preparation: MO, GB, AE-G. All authors reviewed the results and approved the final version of the manuscript.

\section{References}

1. Schneider, R. Theory of Routine Mode Choice Decisions: An Operational Framework to Increase Sustainable Transportation. Transport Policy, Vol. 25, 2013, pp. 128-137.

2. Anable, J., and B. Gatersleben. All Work and No Play? The Role of Instrumental and Affective Factors in Work and Leisure Journeys by Different Travel Modes. Transportation Research Part A: Policy and Practice, Vol. 39, No. 2, 2005, pp. 163-181.

3. Thériault, M., F. Des Rosiers, and F. Joerin. Modelling Accessibility to Urban Services Using Fuzzy Logic: A Comparative Analysis of Two Methods. Journal of Property Investment \& Finance, Vol. 23, No. 1, 2005, pp. 22-54.

4. Buys, L., and E. Miller. Conceptualising Convenience: Transportation Practices and Perceptions of Inner-Urban High Density Residents in Brisbane, Australia. Transport Policy, Vol. 18, No. 1, 2011, pp. 289-297.

5. Hine, J., and J. Scott. Seamless, Accessible Travel: Users' Views of the Public Transport Journey and Interchange. Transport Policy, Vol. 7, No. 3, 2000, pp. 217-226.

6. Johansson, M., T. Heldt, and P. Johansson. The Effects of Attitudes and Personality Traits on Mode Choice. Transportation Research Part A: Policy and Practice, Vol. 40, No. 6, 2006, pp. 507-525.

7. Krizek, K., J. Horning, and A. El-Geneidy. Perceptions of Accessibility to Neighborhood Retail and Other Public Services. In Accessibility and Transport Planning: Challenges for Europe and North America, Edward Elgar, London, 2012, pp. 96-117.

8. Damant-Sirois, G., M. Grimsrud, and A. M. El-Geneidy. What's your Type: A Multidimensional Cyclist Typology. Transportation, Vol. 41, No. 6, 2014, pp. 1153-1169.

9. van Lierop, D., and A. El-Geneidy. Getting Committed: A New Perspective on Public Transit Market Segmentation from Two Canadian Cities. Presented at 94th Annual Meeting of the Transportation Research Board, Washington, D.C., 2015.

10. Manaugh, K., and A. El-Geneidy. Does Distance Matter? Exploring the Links Among Values, Motivations, Home Location, and Satisfaction in Walking Trips. Transportation Research Part A: Policy and Practice, Vol. 50, 2013, pp. 198-208.

11. Abenoza, R., O. Cats, and Y. Susilo. Travel Satisfaction with Public Transport: Determinants, User Classes, Regional Disparities and their Evolution. Transportation Research Part A: Policy and Practice, Vol. 95, 2017, pp. 64-84.

12. Dill, J., and N. McNeil. Four Types of Cyclists? Examination of Typology for Better Understanding of Bicycling Behavior and Potential. Transportation Research Record: Journal of the Transportation Research Board, 2013. 2387: 129-138.

13. Jensen, M. Passion and Heart in Transport: A Sociological Analysis on Transport Behaviour. Transport Policy, Vol. 6, No. 1, 1999, pp. 19-33. 
14. Anable, J. 'Complacent Car Addicts' or 'Aspiring Environmentalists'? Identifying Travel Behaviour Segments Using Attitude Theory. Transport Policy, Vol. 12, No. 1, 2005, pp. 65-78.

15. Statistics Canada. Population of Census Metropolitan Areas, 2016.

16. Krizek, K., and A. El-Geneidy. Segmenting Preferences and Habits of Transit Users and Non-Users. Journal of Public Transportation, Vol. 10, No. 3, 2007, p. 5.

17. Song, Y., and G. J. Knaap. Quantitative Classification of Neighbourhoods: The Neighbourhoods of New SingleFamily Homes in the Portland Metropolitan Area. Journal of Urban Design, Vol. 12, No. 1, 2007, pp. 1-24.

18. Jin, X., E. Beimborn, and M. Greenwald. Impacts of Accessibility, Connectivity and Mode Captivity on Transit Choice. Federal Transit Administration, Washington, D.C., 2004.

19. CBC. Calgary's Economy has Shifted from 'Recession' to Slow 'Recovery,' Economists Predict. CBC News, 2016.
20. Wiebe, K., J. Distasio, and R. Shirtliffe. Confronting the Illusion: Developing a Method to Identify Food Mirages and Food Deserts in Winnipeg. The University of Winnipeg, Institute of Urban Studies, Manitoba, 2016.

21. Vicente, P., and E. Reis. Profiling Public Transport Users through Perceptions about Public Transport Providers and Satisfaction with the Public Transport Service. Public Transport, Vol. 8, No. 3, 2016, pp. 387-403.

22. City of Calgary. Central Business District Cordon Count. http:/www.calgary.ca/Transportation/TP/Pages/Planning/ Transportation-Data/Central-Business-District-CordonCount.aspx. Accessed July 1, 2017.

The Standing Committee on Traveler Behavior and Values (ADB10) peer-reviewed this paper (19-01281). 